\title{
Exploring the influencing factors of continuous crop residue supply: from the perspective of a sustainable and bioenergy-oriented crop cultivation
}

\author{
Xin Long $\mathrm{Xu}^{1,2} \mathbb{D}^{\mathrm{B}}$, Hsing Hung Chen ${ }^{3}$ and $\mathrm{Yi} \mathrm{Li}^{4^{*}}$
}

\begin{abstract}
Background: Crop residues are an important raw material for bioenergy. There is, however, obvious seasonality in crop harvests, and thus, a continuous supply of crop residues and its respective influencing factors should be investigated.
\end{abstract}

Methods: In this paper, the impacts of geographical climatic conditions, characteristics of crops and the macroeconomic status exerted on the continuity of crop residue supply were analysed. Likewise, the effects of various factors on the supply of crop residues were examined.

Results: The results indicate that planting scale, crop diversity, climatic conditions, and topography have a significantly positive impact on a continuous crop residue supply, whereas the planting structure, temperature square term, energy pressure, and the economic development level have a significantly negative one. Finally, a regression-based decomposition method was used to measure the contribution rate of each variable onto the inequalities in the continuous supply of crop residues, which confirms that the impact of characteristics of crops on its continuous supply was the highest. The economic development level is the most important factor that affects the inequalities in the continuity of crop residue supply.

Conclusions: The above results were achieved by using different measurement methods, and based upon the findings obtained, this paper proposes policies and suggestions for ensuring sustainable and bioenergy-oriented crop cultivation.

Keywords: Continuous crop residue supply, Bioenergy, Sustainability, Regression-based decomposition method

\section{Background}

As a result of the dual pressure caused by the scarcity of petrochemical energy and environmental pollution, countries have paid more and more attention to the development and use of bioenergy to replace fossil fuel energy [1-5]. Although the development of bioenergy

*Correspondence: yibsen@163.com

${ }^{4}$ College of Business, Hunan Agricultural University, Changsha 410128, China

Full list of author information is available at the end of the article has played a positive role in mitigating the global energy crisis and reducing environmental pollution [6], bioenergy is currently based primarily on economic "cash" crops such as grain or oil crops, which will not only threaten global food security but also aggravate poverty in some developing countries [7]. China has a large population with a relatively high population density [8]. Water resources are however significantly insufficient [9]. In the event that bioenergy is developed from crops, it will inevitably affect China's food security and the sustainable development of animal husbandry. Crop residues can be original author(s) and the source, provide a link to the Creative Commons licence, and indicate if changes were made. The images or other third party material in this article are included in the article's Creative Commons licence, unless indicated otherwise in a credit line to the material. If material is not included in the article's Creative Commons licence and your intended use is not permitted by statutory regulation or exceeds the permitted use, you will need to obtain permission directly from the copyright holder. To view a copy of this licence, visit http://creativecommons.org/licenses/by/4.0/. The Creative Commons Public Domain Dedication waiver (http://creativeco mmons.org/publicdomain/zero/1.0/) applies to the data made available in this article, unless otherwise stated in a credit line to the data. 
converted into bioenergy through a respective industrial technology, which has an important gross development value. As a global giant in agricultural production, China produces a lot of crop residues. If they could be converted into energy, this might not only solve the problems of energy scarcity and waste disposal, but also improve the rural ecological environment $[10,11]$. However, crop residues are currently not comprehensively and efficiently used in China. Farmers burn some agricultural residues in their fields, which is not only a waste of valuable resources but also causes serious environmental pollution [12]. Therefore, the use of agricultural residues for producing bioenergy has significant economic and ecological benefits [13].

In the basic cycle of agricultural production, crop residues play an important role in preventing soil erosion, maintaining soil fertility and sustainable crop cultivation. In addition, crop residues have long been a major source of both feed for animal husbandry and energy for cooking and heating in rural areas $[14,15]$. At present, due to the development of the emerging bioenergy industry, crop residues have a wider range of uses, such as in edible fungi cultivation and density-compressed board and papermaking. Particularly in the context of the depletion of petroleum resources and a deteriorating ecological environment, bioenergy and bio-based chemical materials have become increasingly important [16], which makes the use of agricultural residues unprecedentedly valuable for various countries. In China, the development of bioenergy and the generation of energy through the planned use of crop residues have become strategic options to solve not only the "Agriculture, Countryside, and Farmer" issues but also the environmental and energy ones [17]. Driven by relevant policies, China's crop residue energy industry has developed rapidly. Crop residue gasification, crop residue solidification moulding, and crop residue power generation have grown substantially [12]. With the rise of the crop residue energy industry, agricultural wastes have also been converted into an important energy resource with economic and social value. As the lasting demand for energy requires a continuous supply of raw materials [18], a discontinuous crop residue supply is critical for a project aiming at their continuous, i.e. "sustainable" and environmentally friendly use.

Most of the existing literature with regard to crop residue supply focuses on three aspects. The first one is to study the total amount of crop residues. Liu et al. [19] have estimated the potential of Canadian crop residues by considering factors such as crop yield and land changes and found that the quantity of potential crop residues amounted to approximately $3730 \times 10^{4} \mathrm{t}$. Roberts et al. [20] have considered crop species, planting area and yield and have calculated the annual dry residual biomass potential in the Partido of General Pueyrredón, Buenos Aires, Argentina. The calculated result of residual biomass potential is approximately $20.5 \times 10^{4} \mathrm{t}$. Haase et al. [21] have applied the planting area of crops and the ratio of grass to crops to evaluate the total amount of available crop residues in Europe through the GIS system.

A further aspect is to evaluate the amount of crop residues to be used as an energy source on the basis of the agricultural residues, which are being returned to the soil and/or being implemented in the collection rate. Tian et al. [22] have studied different crops used as fuel, fertiliser, feed or industrial materials, and concluded that the amount of crop residues that could be used as an energy source in China is approximately $3.44 \times 10^{8} \mathrm{t}$. Chandra and Hemstock [23] have used the crop yield and the crop residue collection rate for calculating Fiji's agricultural biomass potential and obtained a result of 72.67PJ. Zhu et al. [24] have calculated the possible sources of crop residues for China's main crops as 15 Mtce-18.6 Mtce, when crop residues are used in agriculture, industry, and combustion. A further third aspect is to study the impact of factors such as R\&D costs and processing technology on the aggregate economic impact of crop residues. Due to the differences in specific technologies and the evaluation content, scholars have obtained different assessment results with regard to the aggregate economic impact of crop residues. Hoogwijk et al. [25] have modelled the productivity levels and labour input costs in different regions and found that global wasteland and reusable land can provide 130-270EJ of bioenergy annually when the production costs are below $2 \$ / G J$. Stephen et al. [26] have taken transaction and shipping costs into consideration and calculated that the amount of agricultural residues in the Pingda area of Alberta are between $5 \times 10^{4} \mathrm{t}$ and $50 \times 10^{4} \mathrm{t}$. Sun et al. [27] have used the Monte Carlo simulation method to study the crop residue collection rate based on unit purchasing costs, shipping costs and collection costs and found that price coordination is conducive to an increase in the crop residue utilisation rate.

There are only few studies dealing with the continuity of crop residue supply. The continuity of the supply of energy resources is an important parameter of resource quality [28]. On the one hand, competing uses for agriculture residues are rapidly emerging, especially from bioenergy generation. Using cost-benefit analysis (CBA) and life-cycle assessment (LCA), Clare et al. [29] compared the economic feasibility and carbon emission reduction potential of biochar production through pyrolysis, with that of bioenergy production through briquetting and gasification in China. They found that briquetting straw for thermal energy is the most cost-effective carbon emission reduction technology. 
However, the bioelectricity subsidy scheme leads to gasification more financially captivating for investors than both briquetting and pyrolysis. On the other hand, the primary issue of biomass logistics is its storage, primarily when it is characterised by seasonal availability. The existing literature usually adopts the lowest cost storage method available arbitrarily, ignoring the effects this method could have on the total system efficiency [30]. Rentizelas et al. [31] employ the three most frequently used biomass storage methods to analyse a case study. They conclude that the lowest cost storage method consists of the system-wide most efficient solution indisputably. However, low-cost agriculture residue storage methods bear increased safety, health, and technological risks [32].

Therefore, aside from the competing uses and storage factor, the evaluation of other factors affecting the continuity of crop residue supply is an essential issue for the energy-oriented use of crop residues. This paper examines the impacts of factors which are divided into three aspects, climatic and geographical conditions, characteristics of crops, and the macroeconomic status on continuous crop residue supply, providing insights regarding the supply of agricultural residues and facilitating in this way the sustainable development of bioenergy. The structure of this paper is as follows: the following second part provides a literature review, the third one the methodology, the fourth one the results obtained, and the last one includes conclusions, implications and suggestions for future research.

\section{Factors affecting sustainable and environmentally friendly crop residue cultivation}

The continuous crop residue supply index is calculated based on three indicators: the annual total amount of crop residues, their seasonal distribution, and the potential demand [33]. Therefore, the factors affecting these three indicators will also affect the sustainability of the cultivation. Climatic conditions, topography, planting scale and structure, the farming system, crop diversity and the energy pressure, as well as economic development levels have also influenced the sustainability of crop residue supply [34]. These factors can be classified into three types: climatic and geographic conditions, characteristics of crops and the macroeconomic status [35]. Here, the geographic and climatic conditions include two factors, climate and topography. The characteristics of crops are comprised of four factors: planting scale, planting structure, crop diversity, and farming system, whereas the macroeconomic status comprised two factors: economic development level and energy pressure.

\section{Climatic and geographical conditions}

Agriculture is closely related to local climatic conditions. Light, temperature and rainfall have a decisive effect on agriculture. On the other hand, the topography of crop residue production will affect the scale of planting.

\section{Climatic conditions}

The climatic conditions themselves affect the continuity of the supply of agricultural residues in several ways. Firstly, climatic conditions might affect the planting scale [36], which in turn might affect the sustainability of crop residue supply. The total amount and quality of the cultivated land resources and the distribution of water resources in a region are the result of local climatic conditions and social, economic and cultural factors over a long period [37]. In areas with sufficient rain and heat, the cultivated land resources could be more abundant, irrigation could be more convenient, and the multiple farming indices might be higher and the planting scale larger [38]. Secondly, climatic conditions could affect the planting structure [39], which in turn could affect the supply of crop residues. Driven by demand and economic benefits, the scale of horticultural crop planting has gradually expanded nationwide (see Fig. 1). Areas with abundant rain and heat have a competitive advantage for growing horticultural crops, from which it can be inferred that the scale of horticultural crops in these areas is expanding faster. As a result, the proportion of non-straw crops could be rising. Figure 2 compares the proportions of vegetables in different provinces with similar economic development levels, but different climatic conditions. The proportion of vegetables in provinces with higher average annual temperature is significantly higher than that of provinces with lower average annual temperature. Among the eastern provinces, Shanghai and Beijing have the highest proportion of vegetables. In central and western provinces, the proportion of vegetables in Hainan and Guangxi is more than six times higher compared to that in Heilongjiang and Jilin. In the past two decades, Hainan, Guangxi and other central and western provinces have fully exerted their climatic advantages and expanded vegetable production and trade, which has significantly increased the scale of vegetable production. Figure 1 shows that the proportion of vegetables in Hainan has increased sharply from $15.69 \%$ in 1998 to $35.79 \%$ in 2017 . Guangxi has a similar trend of development. In Yunnan, the proportion of vegetables has grown significantly in recent years. The above-mentioned data show that under better climatic conditions, the planting structure could be more biased towards non-straw crops, which might have a negative impact on the supply of crop residues. Thirdly, climatic 

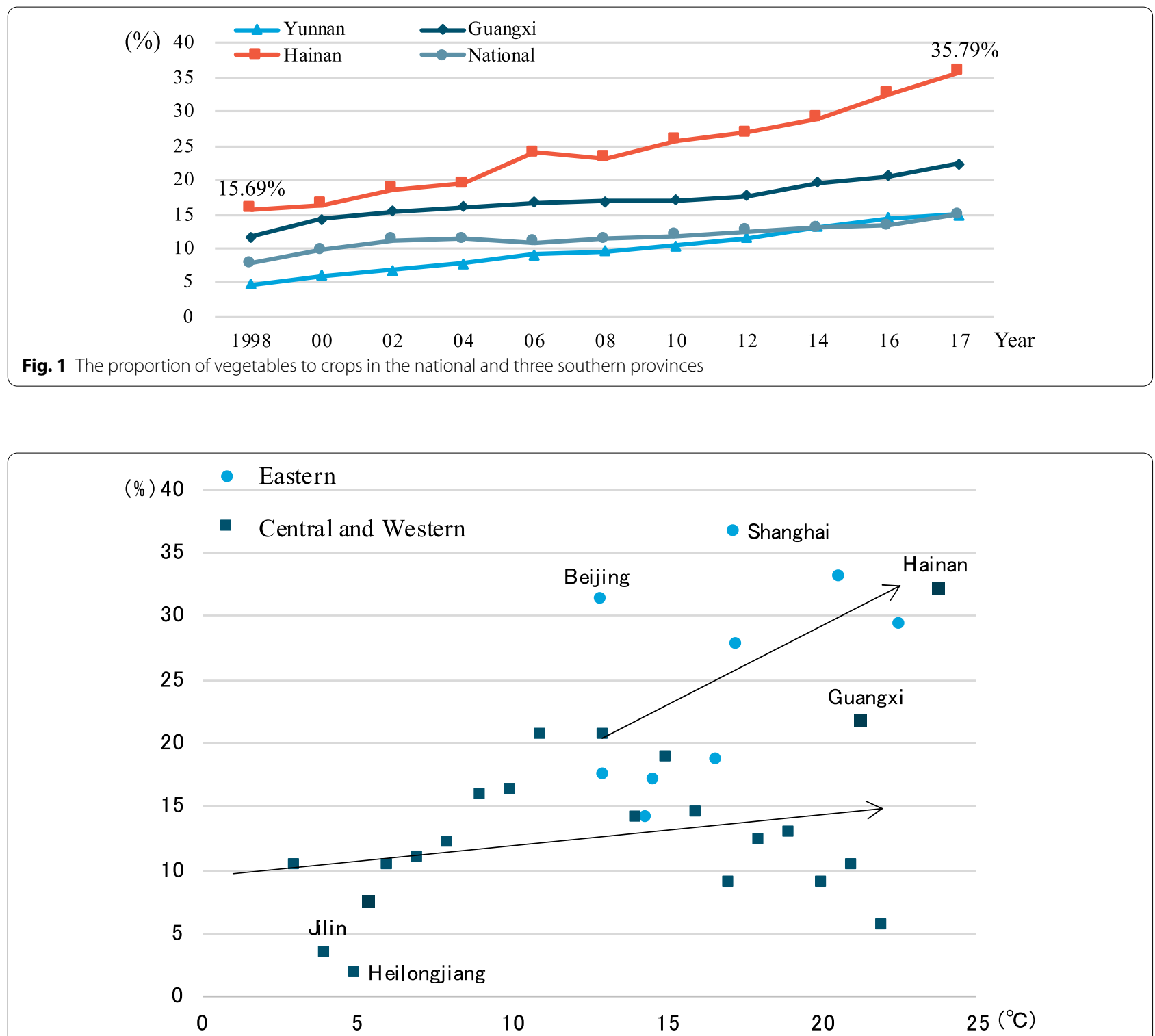

Fig. 2 Climate, economic and vegetable proportion

conditions can determine the diversity of crops [40]. Specific climatic conditions also determine the crop maturity period, which will in turn affect the crop diversity and the seasonal distribution of crop residues.

\section{Topography}

In plains, soil is deep and fertile, construction costs for farmland water conservation facilities are low, and irrigation is also relatively inexpensive [41]. Compared with hills and mountains, plains are better sites for planting. Worldwide, areas with developed planting industries are mostly distributed across plains [42]. Hills and mountains are more suitable for forestry and animal husbandry
[43]. It can be inferred that under the same conditions, the scale of planting in plains is larger than that in mountains and hills. However, different altitudes and ground conditions might cause differences in the local climate, which in turn will lead to differences in planting systems [44]. In areas with the same latitudes, lower temperatures in mountains and hill areas are likely to reduce multiple farming indices.

\section{Characteristics of crops}

There are many factors affecting the continuous supply of crop residues such as planting scale and structure, farming system and crop diversity. The planting scale is 
the most important factor to influence the production of crop residues.

\section{Planting scale and structure}

Crop residues are wastes that are most valuable for cultivation. Planting scale is the primary factor determining the total amount of crop residues [45]. However, in the case of a fixed planting scale, the planting structure has a decisive effect on the total amount of crop residues [46]. Usually, scholars categorise crops into straw crops (e.g., grain, cotton, oil crops, rice and wheat) and nonstraw crops (e.g., vegetables). The higher the proportion of straw crops in total crops, the richer the crop residues would be [47]. Therefore, the larger the planting scale is, the lower the proportion of non-straw crops and the higher the continuity of crop residue supply would be.

\section{Farming system}

The crop maturity period and multiple-crop index reflect the farming system used in agricultural production and determine the scale of planting [48]. The planting scale of multi-cropping on the same land in a certain period of time is often larger than that of a single crop on the same land [49]. In addition, under the same conditions, crop diversity would be reduced under a regime of a "three harvests per year", a "two harvests per year", a "three harvests every 2 years", or a "one harvest per year" farming system, respectively [50, 51]. Therefore, the farming system could affect the seasonal distribution of crop residues.

\section{Crop diversity}

The seasonality of the crop residue harvest depends on the connection between one harvest and the next [52]. The more varieties of crops with different harvest periods during the year are, the closer the continuity of crop residue harvests over time would be [53]. Therefore, crop diversity determines the distribution of crop residues in each month's supply, thus in turn affects the supply sustainability of the residues.

\section{Macroeconomic status}

Macroeconomic factors such as energy pressure and economic development level should also be addressed. These external impacts of economic sustainability are concentrated in the broader economy, taking into account social and environmental impacts. The economic sustainability of crop residues needs to be evaluated at the macroeconomic level. Investment in local energy and more renewable energy resources will increase employment in rural areas, thus internalising the economic value of biomass.

\section{Energy pressure}

Energy shortages and environmental problems caused by the consumption of fossil energy are major challenges in future social and economic development [54]. Under such pressure, the urgency of seeking renewable clean energy to replace fossil fuels is high, and the potential demand for crop residues might be tremendous [55].

\section{Level of economic development}

The economic development level affects the continuity of crop residue supply through a variety of mechanisms. Economic development reduces the scale of crop production and thus restricts a continuous supply of crop residues. The economic development level represents the level of industrialisation and urbanisation [56], while the process of industrialisation and urbanisation in turn requires a large amount of cultivated land [57]. The situation can be more obvious in eastern provinces, while central and western provinces, and in particular, large agricultural provinces, are more responsible for ensuring food security and stabilising the supply of agricultural products, and in this way, take more actions to protect the cultivated land. As shown in Fig. 3, a comparison of the data representing arable land in the provinces in 1998 and 2017 reveals that the area of cultivated land in provinces with faster economic development increases less quickly $[58,59]$. In addition, in Beijing and Shanghai, the area of cultivated land suffered a significant decrease of more than $30 \%$. However, in most central and western provinces, the area of cultivated land increased notably.

In summary, as an agricultural resource, the quantity and quality of crop residues directly depend on planting characteristics [33]. Although geographical and climatic conditions can also affect agricultural production, their influences could be strongly limited, because humans are now more capable of adapting to and transforming the agricultural environment. In contrast, under the conditions of an open market economy, macroeconomic factors and energy pressures have an increasing influence on the supply of crop residues [52, 57]. Therefore, plant topography, planting scale, farming system, and crop diversity have a positive impact on the continuity of crop residue supply; planting structure, energy pressure and economic development level have a negative impact on a continuous supply of crop residues, whereas climatic conditions have a positive or negative impact on this supply. The expected impact of various factors is demonstrated in Table 1. 


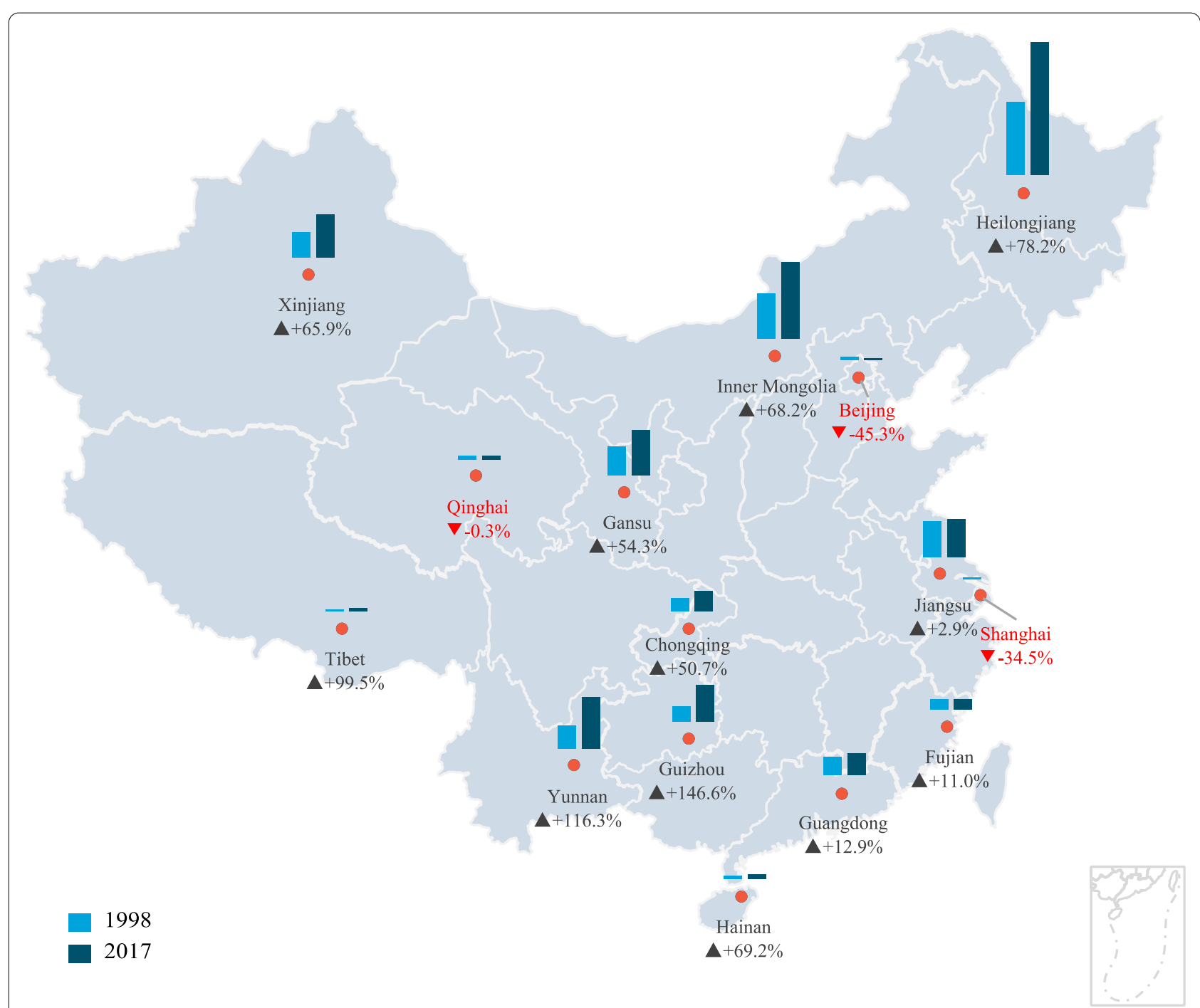

Fig. 3 The comparison of province cultivated area between 1998 and 2017. This figure is generated using Microsoft Excel 2016 created by the National Administration of Survey, Mapping and Geoinformation of China (https://www.nasg.gov.cn), and the map will not have a copyright dispute

Table 1 Description of the variables

\begin{tabular}{lrrllll}
\hline Variables & Mean & St. dev & Max & Min & Expected impact & Definition \\
\hline SSC & 5.12 & 2.53 & 8.5 & 0.83 & $/$ & CRS sustainability coefficient \\
${ }^{\circ} \mathrm{C}$ & 14.87 & 5.03 & 26.01 & 3.84 & + & Temperature \\
${ }^{\circ} \mathrm{C}^{2}$ & 235.71 & 145.81 & 649.12 & 23.07 & - & Temperature squared term \\
PSC & 50.07 & 41.54 & 142.52 & 2.34 & + & Planting scale (million/ha) \\
PST & 14.17 & 7.91 & 36.6 & 1.9 & - & Planting structure (\%) \\
FS & 1.26 & 0.37 & 2.52 & 0.66 & + & Multiple-crop index \\
SDI & 0.71 & 0.11 & 0.86 & 0.45 & + & Simpson Diversity Index \\
EP & 2.75 & 1.24 & 6.71 & 1.05 & - & Energy pressure \\
TGP & 0.53 & 0.51 & 1 & 0 & + & Topography \\
EDL & 0.33 & 0.47 & 1 & 0 & - & Economic development level \\
& & & & &
\end{tabular}




\section{Methodology}

\section{Data sources}

This paper examines panel data of 31 provinces in China from 2008 to 2017 as a research sample. Data with regard to climate temperature, area of cultivated land, and total population are taken from the China Statistical Yearbook [60]. Data regarding the planting areas of various crops were taken from the website of the Ministry of Agriculture and Rural Affairs of China [61] and the total energy consumption data from the China Energy Statistical Yearbook [62].

\section{Variables \\ Dependent variable (the continuous crop residue supply index)}

The proportion of electricity consumption in each region to the national power consumption is used as the weight, which is multiplied by the national monthly crop residue demand to obtain the monthly demand in each region [35]. The authors followed Zhou et al. [33] to calculate the monthly crop residue supply and the supply-demand ratio of crop residues in each region. The steps are as follows.

1 Calculate the monthly crop residue demand. The annual harvest of crop residues in each region is summed up to obtain the national annual harvest, denoted $T$. The national monthly crop residue demand is $D_{m}=T / 12$. The proportion of electricity consumption in region $i$ to the national consumption is given as $P_{i}$, and the monthly demand for crop residues in region $i$ is $D_{i}=D_{m} * P_{i}$.

2 Calculate the supply-demand ratio of crop residues in region $i$. The amount of crop residue harvest in region $i$ in month $j$ is $\mathrm{HAY}_{i j}$, the supply is $S_{i j}$, the remaining supply is $R_{i j}$, and the supply-demand ratio is $\mathrm{SDP}_{i j}$. The supply in January (month 1 ) is equal to the amount of harvest, that is, $S_{i 1}=\mathrm{HAY}_{i 1}$. If $S_{i 1} \geq D_{i}$; next set $\mathrm{SDP}_{i 1}=1, R_{i 1}=S_{i 1}-D_{i}$. If $S_{i 1}<D_{i}$; then $\mathrm{SDP}_{i 1}=S_{i 1} / D_{i}, R_{i 1}=0$.

3 Calculate the supply-demand ratio of crop residues in February (month 2). If $R_{i 1}<D_{i}$, then $S_{i 2}=R_{i 1}+\mathrm{HAY}_{i 2}$. Here, if $S_{i 2} \geq D_{i}$, then set $\mathrm{SDP}_{i 2}=1, \quad R_{i 2}=S_{i 2}-D_{i}$. If $S_{i 2}<D_{i}$; then $\mathrm{SDP}_{i 2}=S_{i 2} / D_{i}, \quad R_{i 2}=0$. If $R_{i 1} \geq D_{i}$, then set $\mathrm{SDP}_{i 2}=1, S_{i 2}=\mathrm{HAY}_{i 2}$.

4 Calculate the supply-demand ratio of crop residue in region $i$ from the third month to the 12th month. Regarding the size of $R_{i j}$, follow step (3) and calculate the supply-demand ratio of crop residue in every month.
According to the monthly supply-demand ratio of crop residues, one can ascertain which months of crop residue supply meet the demand for the year and which months indicate the supply-demand gap as well as the degree of shortage as a basis for the evaluation of the continuity of crop residue supply. To facilitate the comparison of crop residue supply between different regions, the equation for the supply sustainability coefficient is as follows:

$$
\mathrm{SSC}_{i}=\sum_{j=1}^{12} \mathrm{SDP}_{i j}
$$

where $\mathrm{SSC}_{i}$ represents the supply sustainability coefficient. $j$ refers to the month. $\mathrm{SDP}_{i j}$ is the supply-demand ratio of crop residues in region $i$ in month $j$. The value of $\mathrm{SDP}_{i j}$ is between 0 and 1 , and the value of $\mathrm{SSC}_{i}$ is between 0 and 12. The higher the value of $\mathrm{SSC}_{i}$ is, the more sustainable the crop residue supply would be. When $\mathrm{SSC}_{i}=12$, this indicates that the monthly crop residue supply in region $i$ can fully meet demand, and the crop residue supply is perfectly sustainable. When $\mathrm{SSC}_{i}=0$, this indicates that there is no crop residue supply throughout a year.

\section{Independent variables}

\section{Climatic conditions}

The climatic conditions $\left({ }^{\circ} \mathrm{C}\right)$ can be measured by using different indicators, such as climate and rainfall. As the temperature might reflect north-south differences and the correlation coefficient between the interprovincial temperature and the precipitation might exceed 0.7 [63], this paper uses the annual average temperature of provincial capital cities to evaluate the climatic conditions. In order to examine the critical point of the net effect of the climatic conditions on the continuity of crop residue supply, the temperature squared term $\left({ }^{\circ} \mathrm{C}^{2}\right)$ is introduced as an independent variable.

2 Planting scale

The planting scale (PSC) is based on the measured area of crop planting.

3 Planting structure

The planting structure (PST) is based on the proportion of the measured planted area.

4 Farming system

The farming system (FS) is based on the measured multiple-crop index [64]:

$$
\mathrm{FS}=\frac{\mathrm{TAC}}{\mathrm{TCLA}} * 100 \%,
$$


where FS represents the multiple-crop index, TAC represents the total area of crops throughout the year, and TCLA represents the total cultivated land area.

5 Crop diversity

The crop diversity is examined using the Simpson Diversity Index (SDI), which is estimated using the following equation:

$$
\mathrm{SDI}=\left(1-\sum_{i=1}^{s} p_{i}^{2}\right),
$$

where $S$ is the number of species and $P_{i}$ refers to the ratio of the planting area of crop $i$. The value of SDI is between 0 and 1 . The greater the value of SDI is, the higher the crop diversity would be. Ten species of crops were examined in this paper, including potato, canola, winter wheat, spring wheat, early rice, middle rice, late rice, peanut, corn, and soybean.

6 Energy pressure

The energy pressure (EP) is determined from the energy consumption per capita [55].

\section{Control variables}

This paper also uses "plains or not" and "eastern province or not" as the proxy variables for the topography (TGP) and the economic development level (EDL), respectively [28]. Sixteen provinces, including Beijing, Tianjin, Hebei, Liaoning, Jilin, Heilongjiang, Shandong, Shanghai, Jiangsu, Anhui, Jiangxi, Henan, Hubei, Hunan, Chongqing, and Sichuan, are classified as provinces in plains, and their value of the control variable of "plains or not" is 1. For other provinces, the value is 0 [65]. Nine provinces, including Beijing, Tianjin, Hebei, Shandong, Jiangsu, Shanghai, Zhejiang, Fujian and Guangdong, are classified as eastern provinces, and their value of the control variable of "eastern province or not" is 1 . For other provinces, the value is 0 [1]. Table 1 lists the definition and the statistical description of each variable.

\section{Measurement}

\section{Regression model}

Accordingly, the following regression model is established:

$$
\operatorname{SSC}_{i t}=a_{0}+\sum_{1}^{n} \beta_{n} X_{i t}+\varepsilon_{i t},
$$

where $\mathrm{SSC}_{i t}$ represents the crop residue supply sustainability coefficient in province $i$ in year $t . X_{i t}$ represents the independent variables, including the ${ }^{\circ} \mathrm{C},{ }^{\circ} \mathrm{C}^{2}$, PSC, PST, SDI, EP, FS, and plains and eastern province dummies. $\varepsilon_{i t}$ is the random error term.

\section{Measurement of the inequality in crop residue supply continuity}

Based on the study by Shorrocks [66] and the regression decomposition method employed in early studies [34, 67], this paper proposes a regression equation-based inequality decomposition method that uses the coefficient of variation $\mathrm{CV}(\bullet)$ to measure the inequality in interprovincial continuity of crop residue supply. At first, the value of $\beta$ should be estimated based on the results of Eq. (4). Thereafter, the value SS $\mathrm{S}$ of SSC should be estimated, and then the value S $\ddot{S} C$ of SSC should be calculated without considering the constant term. Finally, the regression decomposition should be realised step by step.

Step 1: The contribution of the residual and the constant term to CV(SSC) should be calculated:

$$
\begin{aligned}
& C_{\varepsilon}=\mathrm{CV}(\mathrm{SSC})-\mathrm{CV}(\mathrm{SBC}), \\
& C_{a}=\mathrm{CV}(\mathrm{SBC})-\mathrm{CV}(\mathrm{SBC})
\end{aligned}
$$

Step 2: The contribution of each variable to CV(SSC) should be estimated separately. The value of $X$ is different for the different provinces. $X_{i}$ should be replaced by the sample mean $\bar{X}_{i}$ to eliminate the difference in $X_{i}$. After the replacement, the value of SSC should be calculated again, which is represented as SSC. The difference estimated by SSC is represented as $\mathrm{CV}(\overline{\mathrm{SSC}})$, which is determined by using the difference after excluding $X_{i}$ from $X$. Similarly, replace $X_{i}$ and $X_{j}$ with $\bar{X}_{i}$ and $\bar{X}_{j}$, which can eliminate the differences in $X_{i}$ and $X_{j}$ at the same time. After the replacement, the value of SSC should be calculated again, which is represented as ${ }{ }^{2} C_{i j}$. The difference measured by using $S S C_{i j}$ is represented as $\mathrm{CV}\left(\mathrm{SSC}_{\mathrm{ij}}\right)$, which in turn is used to eliminate further differences in $X . C_{x}^{m n}$ represents the $n$th contribution of variable $x$ to the inequality in the $m$ th round. After calculating the contribution for each round, the contribution of variable $x$ in the $m$ th round is obtained:

$$
C_{x}^{m}=\sum_{n=1}^{N_{m}} C_{x}^{m n} / N_{m}
$$

where $C_{x}^{m}$ represents the contribution of variable $x$ in the $m$ th round. $N_{m}=(9-1) ! /((9-m) !(m-1) !)$. Then the contribution of variable $x$ to the inequality in interprovincial continuity of crop residue supply is obtained in the following, where $I$ represents the province: 


$$
C_{x}=\sum_{m=1}^{9} I_{x}^{m} / 9 .
$$

Step 3: The contribution rate of each factor should be calculated. The contribution rate of the variable $x$ to the inequality in interprovincial continuity of crop residue supply is then calculated as follows. The calculation of the contribution rates of the residual term and the constant term is carried out in the same way:

$$
\mathrm{CI}_{x}=\frac{C_{x}}{\mathrm{CV}(\mathrm{SSC})} * 100 \% .
$$

\section{Results and discussion \\ Model test}

Cross-sectional heteroscedasticity, sequence correlation, and cross-sectional correlation are common problems in panel data model estimation. Reed and Ye [68] employed the Feasible Generalized Least Squares (FGLS) estimator and used three indicators, HETCOFE, RHOHAT, and CSCORR, to test whether the sample data have cross-sectional heteroscedasticity, sequence correlation, and cross-sectional correlation, respectively. In this paper, the three factors were calculated based on the method mentioned above. The results are shown in Table 2. The value of HETCOFE is 3.17 and passes the $5 \%$ significance level test and indicates the existence of heterogeneity between the sections. The value of RHOHAT is 0.72 and passes the $1 \%$ significance level test and indicates the existence of a sequence correlation. The value of CSCORR is 0.55 , but the $P$ value is non-significant and indicates that there is no cross-sectional correlation. Therefore, this paper focuses on solving the problems of cross-sectional heteroscedasticity and sequence correlation in model estimation. According to Reed and Ye [68] and provided the number of sections exceeds the number of time sequences, the HETCOFE would be higher than 1.67, the FGLS (the groupwise heteroscedasticity) and the FGLS (the groupwise heteroscedasticity + serial correlation) would represent two relatively suitable estimation methods. Given that the sample data have an obvious sequence correlation, in this paper the parameter estimation is carried out by using the FGLS (the groupwise heteroscedasticity + serial correlation).

\section{Regression results}

The results in Table 3 demonstrate that the signs of most estimated parameters are consistent with the expectations. From the significance of the variables, except for the constant term, the $t$ tests for all the coefficient estimates of the variables are significant: FS is significant at a $10 \%$ level, and ${ }^{\circ} \mathrm{C}$ and ${ }^{\circ} \mathrm{C}^{2}$ are also significant at a $5 \%$ level; the other variables are significant at a $1 \%$ level. The regression results verify the previous inference that temperature has a significantly positive impact on the continuity of crop residue supply, but when the temperature reaches a certain level, it begins to have a negative net impact on the supply. A further approximation using the estimated coefficients of ${ }^{\circ} \mathrm{C}$ and ${ }^{\circ} \mathrm{C}^{2}$ indicates that an

\begin{tabular}{lll}
$\begin{array}{l}\text { Table 3 Results } \\
\text { heteroscedasticity }\end{array}$ & $\begin{array}{c}\text { of } \\
\text { serial correlation) }\end{array}$ & $\begin{array}{c}\text { FGLS } \\
\text { (groupwise }\end{array}$ \\
\hline Variables & Coefficient & Z value \\
\hline $\mathrm{C}$ & -0.642 & -0.77 \\
${ }^{\circ} \mathrm{C}$ & $0.147^{* *}$ & 3.24 \\
${ }^{\circ} \mathrm{C}^{2}$ & $-0.004^{* *}$ & -2.17 \\
$\mathrm{TGP}$ & $0.672^{* * *}$ & 3.51 \\
$\mathrm{PSC}$ & $0.009^{* * *}$ & 4.91 \\
$\mathrm{PST}$ & $-0.035^{* * *}$ & -3.17 \\
$\mathrm{FS}$ & $0.404^{*}$ & 8.13 \\
$\mathrm{SDI}$ & $6.941^{* * *}$ & 8.01 \\
$\mathrm{EP}$ & $-0.251^{* * *}$ & -4.03 \\
$\mathrm{EDL}$ & $-1.771^{* * *}$ & -6.59 \\
Wald test & $P=0.00$ & \\
$T$ & 10 & \\
$N$ & 31 & \\
\hline
\end{tabular}

******* Significant at $1 \%, 5 \%$, and $10 \%$ levels, respectively

\begin{tabular}{|c|c|c|c|c|c|}
\hline & $\begin{array}{l}\text { Groupwise } \\
\text { heteroscedasticity } \\
\text { (HETCOEF) }\end{array}$ & Serial correlation (RHOHAT) & $\begin{array}{l}\text { Cross-sectional } \\
\text { dependence } \\
\text { (CSCORR) }\end{array}$ & $\begin{array}{l}\text { Number of cross- } \\
\text { sections }(N)\end{array}$ & $\begin{array}{l}\text { Number } \\
\text { of time } \\
\text { periods }(T)\end{array}$ \\
\hline \multicolumn{6}{|c|}{ Experiments where $N>T$} \\
\hline$H_{0}$ & $\begin{array}{l}\text { No groupwise heterosce- } \\
\text { dasticity }\end{array}$ & No serial correlation & $\begin{array}{l}\text { No cross-sectional } \\
\text { dependence }\end{array}$ & - & - \\
\hline Measure & 3.17 & 0.72 & 0.55 & 31 & 10 \\
\hline$P$ value & $0.014^{* *}$ & $0.007^{* * *}$ & 0.284 & - & - \\
\hline
\end{tabular}

Table 2 Model test of panel data

The measures HETCOEF, RHOHAT and CSCORR are described in Reed and Ye [68]

$* * * * *,{ }^{*}$ Significant at $1 \%, 5 \%$, and $10 \%$ levels, respectively 
increase in the average annual temperature of the provincial capital over $22^{\circ}$ affected the climatic conditions in a way that they began producing a net negative impact on sustainability. This means that the superior climatic conditions in Guangdong, Guangxi, Hainan and other provinces have greatly increased the proportion of vegetables in planting, which in turn restricts the supply of crop residues. This is also consistent with the expectations given in this paper. Planting scale, crop diversity, multiple-crop index, and topography have a positive impact on sustainability, while the EDL, planting structure, and EP have a negative impact.

Parameter estimation revealed a marginal influence of various variables on the continuity of crop residue supply, and the necessity for a further examination of the contribution rates of various variables to the inequality in interprovincial crop residue supply to sort the variables according to the contribution rate and distinguish the importance of each variable. Therefore, the contribution rate of each variable is measured by a regression-based decomposition method.

\section{The contribution rate of variables founded upon regression-based decomposition}

Table 4 demonstrates the regression-based decomposition results. The explanatory power of the characteristics of crops for the continuity of crop residue supply accounts for $42.12 \%$ of the explanatory power of all variables, which demonstrates that the impact of the characteristics of crops on the supply of crop residues exceeds that of the geographical and climatic conditions and the

Table 4 Results of regression-based decomposition

\begin{tabular}{llll}
\hline Feature categories & Variables & $\begin{array}{l}\text { Contribution } \\
\text { to CV }\end{array}$ & Percentage (\%) \\
\hline Geographical and & ${ }^{\circ} \mathrm{C}$ & 3.62 & 7.71 \\
Climatic conditions & ${ }^{\circ} \mathrm{C}^{2}$ & 0.07 & 0.15 \\
& $\mathrm{TGP}$ & 1.37 & 2.92 \\
Sum & & 5.06 & 10.77 \\
Characteristics of crops & PSC & 6.75 & 14.37 \\
& PST & 2.62 & 5.58 \\
& FS & 1.79 & 3.81 \\
Sum & SDI & 8.63 & 18.37 \\
Macroeconomic status & EP & 19.79 & 42.12 \\
& EDL & 4.57 & 9.73 \\
Sum & & 9.03 & 19.22 \\
& $a$ & 13.6 & 28.95 \\
& $\varepsilon$ & 1.69 & 3.60 \\
Sum & & 6.84 & 14.56 \\
Total & & 8.53 & 18.16 \\
\hline
\end{tabular}

macroeconomic status. Geographicaland climatic conditions account for only $10.77 \%$ in terms of explanatory power, indicating that its influence is very limited, while the macroeconomic status accounts for $28.95 \%$, indicating a relatively higher influence.

As shown in Table 4, the EDL accounts for the largest proportion of factors that affect the inequality of a continuous crop residue supply and indicates that the economic development gap is the most important factor contributing to a lower continuity of crop residue supply in the Eastern provinces compared to the central and western provinces. In the short term, when the economic development pattern in the eastern, central and western regions stabilises, the inequality of crop residue supply sustainability between the eastern provinces and the central and western provinces will remain large. In the long run, if the "Western Development" and "Revitalisation of the Old Industrial Bases in the Northeast" strategies are able to achieve remarkable results, and the central region is able to grow and narrows the regional gap, the inequality of continuous crop residue supply between the regions will presumably shrink.

While the inequality in the EDL can best explain the differences in crop residue supply between the economic regions, the SDI and PSC can best explain the inequality in the interprovincial crop residue supply, which further verifies that the seasonality of crop harvesting and planting scale are important factors that constrain a sustainable crop residue supply. Crop diversity accounts for $18.37 \%$ of the inequality in the continuity of crop residue supply, and the planting scale accounts for $14.37 \%$.

For provinces with different climatic conditions, the continuity of crop residue supply differs markedly. A larger proportion of inequality is caused by the climatic conditions given by the measured temperature. When global warming is a certain and irreversible fact, and climatic conditions in the northern regions improve, the climatic differences between the regions shrink, thereby narrowing the gap between the regional crop residue supply differences. The impact of ${ }^{\circ} \mathrm{C}^{2}$ on inequality in the continuity of crop residue supply is very weak.

Another significant factor is the EP. With economic development and the division of labour between the regions, the demand for and consumption of energy in different regions show greater differences, which means that EP plays an increasingly important role in the inequality in the continuity of crop residue supply.

The contribution rate of PST onto the inequality is only $5.58 \%$. The transformation of the consumption structure caused by an increase in the income level entails changes in the demand structure of agricultural products. However, this kind of change exists in almost all regions. In the long run, the gap in the planting 
structure between the regions must be reduced, which in turn would lead to a reduction in the inequality in the continuity of crop residue supply. The topography and the FS contribute less to this inequality.

\section{Robustness check}

The above decomposition of the interprovincial inequality in the continuity of crop residue supply is based on the method proposed by Shorrocks [69] and Fields and Yoo [70]. The measurement indicator used in this method is the coefficient of variation, but some scholars believe that the coefficient of variation "exaggerates" the degree of inequality [67, 71]. Therefore, another regression decomposition method [72] was used and the Gini coefficient and the Theil $\mathrm{T}$ index and $\mathrm{L}$ index were applied to perform the robustness test for the results above. The robust results are shown in Table 5 .

The results in Table 5 demonstrate that, according to the Gini coefficient, with regard to the proportion of the contribution of various factors to the inequality in the continuity of crop residue supply, the ranking of factors shows the characteristics of crops (with 42.36\%), the macroeconomic status (with $33.48 \%$ ), and the geographical and climatic conditions (with 10.59\%). The ranking of various factors is the same as that achieved when using the Theil $\mathrm{T}$ index and $\mathrm{L}$ index. Comparing the results of the robustness test with those in Table 4 revealed that the contribution rate of each factor to the inequality is slightly different, but the ranking is the same. Therefore, the above conclusions have a good robustness.

\section{Conclusions and implications Conclusion}

In this paper, interprovincial panel data were used for analysing the factors that affect the continuity of crop residue supply and confirm that the PSC, the SDI, ${ }^{\circ} \mathrm{C}$ and the topography have a significantly positive impact on the continuity, while the PST, the ${ }^{\circ} \mathrm{C}^{2}$, the EP, and the EDL have a significantly negative impact. The regressionbased decomposition method was further employed for measuring the contribution rate of each factor on the interprovincial inequality in the continuity of crop residue supply. The results showed that characteristics of crops have the highest explanatory power for a continuous and environmental-friendly crop residue supply, followed by the macroeconomic status, and the geographical and climatic conditions that have a very limited explanatory power. Judging from a single factor, the EDL between eastern provinces and central and western provinces is the most important factor causing the regional inequality in the continuity of crop residue supply. The SDI and the PSC have the highest explanatory power for inequality, followed successively by the EP, climatic conditions, the PST, the FS, and topography.

\section{Implications}

Based on these conclusions, the following implications could be summarised:

In the short term, neither geographical and climatic conditions, as well as characteristics of crops, nor the macroeconomic conditions will change significantly. Therefore, it is more difficult to improve the continuity of crop residue supply by changing these factors. Thus,

Table 5 Results of robustness analysis

\begin{tabular}{|c|c|c|c|c|c|c|c|}
\hline Feature categories & Variables & Gini & $\%$ & Theil-L & $\%$ & Theil-T & $\%$ \\
\hline \multirow{3}{*}{$\begin{array}{l}\text { Geographical and climatic } \\
\text { conditions }\end{array}$} & ${ }^{\circ} \mathrm{C}$ & 2.51 & 5.45 & 1.12 & 3.06 & 1.17 & 3.00 \\
\hline & ${ }^{\circ} \mathrm{C}^{2}$ & 0.85 & 1.85 & 0.64 & 1.75 & 0.73 & 1.87 \\
\hline & TGP & 1.52 & 3.30 & 1.13 & 3.08 & 1.55 & 3.97 \\
\hline Sum & & 4.88 & 10.59 & 2.89 & 7.89 & 3.45 & 8.84 \\
\hline \multirow[t]{4}{*}{ Characteristics of crops } & PSC & 6.91 & 15.00 & 5.31 & 14.49 & 5.58 & 14.30 \\
\hline & PST & 2.47 & 5.36 & 1.23 & 3.36 & 1.83 & 4.69 \\
\hline & FS & 1.32 & 2.87 & 0.13 & 0.35 & 0.34 & 0.87 \\
\hline & SDI & 8.81 & 19.13 & 7.51 & 20.49 & 9.13 & 23.39 \\
\hline Sum & & 19.51 & 42.36 & 14.18 & 38.69 & 16.88 & 43.25 \\
\hline \multirow[t]{2}{*}{ Macroeconomic status } & EP & 5.73 & 12.44 & 4.12 & 11.24 & 3.15 & 8.07 \\
\hline & $\mathrm{EDL}$ & 9.69 & 21.04 & 8.01 & 21.86 & 8.07 & 20.68 \\
\hline \multirow[t]{3}{*}{ Sum } & & 15.42 & 33.48 & 12.13 & 33.1 & 11.22 & 28.75 \\
\hline & $a$ & 1.22 & 2.65 & 1.32 & 3.60 & 1.25 & 3.20 \\
\hline & $\varepsilon$ & 5.03 & 10.92 & 6.13 & 16.73 & 6.23 & 15.96 \\
\hline Sum & & 6.25 & 13.57 & 7.45 & 20.33 & 7.48 & 19.16 \\
\hline Total & & 46.06 & 100 & 36.65 & 100 & 39.03 & 100 \\
\hline
\end{tabular}


new ideas should be considered to improve the continuity. First, this paper only studies the continuity of crop residue supply from the perspective of resource endowment, while ignoring the socio-economic factors-straw storage. When the total amount of crop residue and the distribution of straw harvest season are fixed, storage is an essential factor to determine the continuity of crop residue supply. The conclusion of Rentizelas et al. [31] reveals the necessity and importance of strengthening straw storage capacity in the short term. Second, the continuous supply of crop residue differences among provinces highlights the comparative advantages and disadvantages of the regions in implementing energy-based agriculture, which is represented by the respective production of bioenergy. Giving full play to comparative advantage and an interprovincial crop residue energy circulation, the EP of the developed provinces can not only be reduced, but also provides a new engine for the economic development of agricultural areas. Finally, there are some period lags in crop harvest among the regions. Therefore, the cross-regional deployment of crop residue is also an idea to solve the problem of a persistent shortage of short-term supply.

In the long run, the characteristics of crops and the macroeconomic status will change. However, the macroeconomic status is more dependent on the overall economic development of the country. Since the characteristics of crops have the most significant influence on the sustainability of crop residue supply, efforts for their improvement should focus on adjusted planting characteristics. Large agricultural provinces can improve the continuity of crop residue supply by adjusting the PSC, the PST, and the crop diversity, making full use of the advantages of resources and of the development of the energy potential of the agriculture. In addition, large agricultural provinces should enhance the protection of cultivated land, ensure a stable growth of grains, cotton, and oil crops, and stabilise and expand the planting scale of straw crops, thus guaranteeing the total amount of crop residues. At the same time, attention should be paid to the new varieties of crops harvested in the gaps between the cultivation of traditional crops and the rational encouraging of farmers and regions to carry out a diversified crop production to narrow the time gap between the harvests. It is easier to reduce the seasonal fluctuations in straw crop harvests, which will in turn improve a sustainable and continuous environmental-friendly crop residue cultivation.

\section{Future research directions}

Please note that in this research paper such factors were examined that affect the continuity of crop residue supply from the perspective of resource characteristics without considering storage factors. Therefore, future research studies should include the storage in the analytical framework, and take the costs and profits of storage into consideration, as well as analyse the impacts of storage on a continuous and sustainable crop residue cultivation.

\begin{abstract}
Abbreviations
CBA: Cost-benefit analysis; Cl: Contribution rates; CV: Coefficient of variation; $C_{x}^{m}$ : Contribution of variable $x$ in the $m$ th round; $D$ : National monthly crop residue demand; EDL: Economic development level; EP: Energy pressure; FGLS: Feasible Generalized Least Squares; FS: Farming system; HAY: Amount of crop residue harvest; $L C A$ : Life-cycle assessment; $P$ : The proportion of electricity consumption to the national consumption; PSC: Planting scale; PST: Planting structure; R: Remaining supply; R\&D: Research and development; S: Supply; SDP: Supply-demand ratio; SDI: Simpson Diversity Index; SSC: Supply sustainability coefficient; $T$ : National annual harvest; TGP: Topography; $X$ : Independent variables.
\end{abstract}

\section{Acknowledgements}

We sincerely thank the editor and reviewers for their very valuable and professional comments.

\section{Authors' contributions}

The manuscript is designed by XLX. The data set was collected by YL. Analysis of data was performed by XLX and HHC. Finally, the manuscript was written by XLX, HHC and YL. All authors read and approved the final manuscript.

\section{Funding}

This work was supported by the Youth Project of Humanities and Social Sciences of Ministry of Education in China [Grant numbers 18YJC630213]; China Postdoctoral Science Foundation [2020M670473]; National Social Science

Foundation of China [Grant numbers 19CGL030]; Natural Science Foundation of Hunan Province [Grant numbers 2019JJ50382, 2018JJ3247]; and Key Project of Hunan Education Department [Grant numbers 19A292].

\section{Availability of supporting data}

The datasets used and/or analysed during the current study are available from the corresponding author on reasonable request.

\section{Ethics approval and consent to participate}

The submitted paper has not been published previously, is not under consideration for publication elsewhere, its publication is approved by all authors and tacitly or explicitly by the responsible authorities where the work was carried out.

\section{Consent for publication}

If accepted, it will not be published elsewhere in the same form, in English or in any other language, including electronically without the written consent of the copyright-holder.

\section{Competing interests}

The authors declare that they have no competing interests.

\section{Author details}

${ }^{1}$ College of Tourism, Hunan Normal University, Changsha 410081, China. ${ }^{2}$ Institutes of Science and Development, Chinese Academy of Sciences, Beijing 100190, China. ${ }^{3}$ School of Business, Macau University of Science and Technology, Taipa, Macau, China. ${ }^{4}$ College of Business, Hunan Agricultural University, Changsha 410128, China.

Received: 18 January 2020 Accepted: 23 September 2020

Published online: 02 October 2020 


\section{References}

1. $\mathrm{Xu} \mathrm{XL}$, Chen HH (2018) Examining the efficiency of biomass energy: evidence from the Chinese recycling industry. Energy Policy 119:77-86. https://doi.org/10.1016/j.enpol.2018.04.020

2. Li J, Li J, Zhu X (2020) Risk dependence between energy corporations: a text-based measurement approach. Int Rev Econ Finan 68:33-46. https:// doi.org/10.1016/j.iref.2020.02.009

3. Wei L, Li G, Zhu X, Sun X, Li J (2019) Developing a hierarchical system for energy corporate risk factors based on textual risk disclosures. Energy Econ 80:452-460. https://doi.org/10.1016/j.eneco.2019.01.020

4. Sun X, Hao J, Li J (2020) Multi-objective optimization of crude oil-supply portfolio based on interval prediction data. Ann Oper Res. https://doi. org/10.1007/s10479-020-03701-w

5. Ji Q, Li J, Sun X (2019) New challenge and research development in global energy financialization. Emerg Mark Finan Trade 55(12):2669-2672. https://doi.org/10.1080/1540496X.2019.1636588

6. Qiao S, Xu XL, Liu CK, Chen HH (2016) A panel study on the relationship between biofuels production and sustainable development. Int J Green Energy 13(1):94-101. https://doi.org/10.1080/15435075.2014.910784

7. de Oliveira BR, Carvalho JLN, Lal R, de Figueiredo EB, de Oliveira BG, La Scala N (2018) Sustainability of sugarcane production in Brazil. A review. Agron Sustain Dev 38(2):13

8. Xu XL, Shun C, Li Y, Zhou N (2020) The effects of environmental management and debt financing on sustainable financial growth in the tourism industry. SAGE Open 10(3):1-12. https://doi.org/10.1177/2158244020 948530

9. Qian L, Wang Z, Wang H, Deng C (2020) An improved method for predicting water shortage risk in the case of insufficient data and its application in Tianjin. China J Earth Syst Sci 129(1):48. https://doi.org/10.1007/s1204 0-019-1299-y

10. Chen Q, Liu TB (2017) Biogas system in rural China: upgrading from decentralized to centralized? Renew Sustain Energy Rev 78:933-944

11. Xu XL, Yang XN, Zhan L, Liu CK, Zhou ND, Hu MM (2017) Examining the relationship between intellectual capital and performance of listed environmental protection companies. Environ Prog Sustain Energy 36(4):1056-1066. https://doi.org/10.1002/ep.12572

12. Xu XL, Chen HH, Li Y, Chen QX (2019) The role of equity balance and executive stock ownership in the innovation efficiency of renewable energy enterprises. J Renew Sustain Energ 11(5):1-11. https://doi. org/10.1063/1.5116849

13. Paine LK, Peterson TL, Undersander DJ, Rineer KC, Bartelt GA, Temple SA Sample DW, Klemme RM (1996) Some ecological and socio-economic considerations for biomass energy crop production. Biomass Bioenergy 10(4):231-242. https://doi.org/10.1016/0961-9534(95)00072-0

14. Toklu E (2017) Biomass energy potential and utilization in Turkey. Renew Energy 107:235-244. https://doi.org/10.1016/j.renene.2017.02.008

15. Renzaho AMN, Kamara JK, Toole M (2017) Biofuel production and its impact on food security in low and middle income countries: implications for the post-2015 sustainable development goals. Renew Sustain Energy Rev 78:503-516. https://doi.org/10.1016/j.rser.2017.04.072

16. Xu XL, Chen HH (2020a) Exploring the innovation efficiency of new energy vehicle enterprises in China. Clean Technol Environ Policy. https:// doi.org/10.1007/s10098-020-01908-w

17. Xu XL, Chen HH, Zhang RR (2020) The impact of intellectual capital efficiency on corporate sustainable growth-evidence from smart agriculture in China. Agriculture 10(6):199. https://doi.org/10.3390/agriculture1006 0199

18. Xu XL, Sun $\mathrm{CH}$, Chen HH (2019) How diversified fuel-fired power enterprises keep their competitive advantages to reach sustainable development. Environ Prog Sustain Energy 38(1):137-142. https://doi. org/10.1002/ep.12938

19. Liu TT, McConkey B, Huffman T, Smith S, MacGregor B, Yemshanov D, Kulshreshtha S (2014) Potential and impacts of renewable energy production from agricultural biomass in Canada. Appl Energy 130:222-229. https://doi.org/10.1016/j.apenergy.2014.05.044

20. Roberts JJ, Cassula AM, Prado PO, Dias RA, Balestieri JAP (2015) Assessment of dry residual biomass potential for use as alternative energy source in the party of General Pueyrredon, Argentina. Renew Sustain Energy Rev 41:568-583. https://doi.org/10.1016/j.rser.2014.08.066
21. Haase M, Rosch C, Ketzer D (2016) GIS-based assessment of sustainable crop residue potentials in European regions. Biomass Bioenergy 86:156-171. https://doi.org/10.1016/j.biombioe.2016.01.020

22. Tian YS, Zhao LX, Sun LY, Meng HB (2011) Analysis and evaluation on agricultural biomass resources. Eng Sci 13(2):24-28

23. Chandra WV, Hemstock SL (2015) A biomass energy flow chart for Fiji. Biomass Bioenergy 72:117-122. https://doi.org/10.1016/j.biomb ioe.2014.11.010

24. Zhu KW, Liu Z, LÜ ZC, Pu GQ, Guo W (2015) The ecological development potential and time-space analysis of Chinese main agricultural crop biomass energy. Sci Agric Sin 48(21):4285-4301

25. Hoogwijk M, Faaij A, de Vries B, Turkenburg W (2009) Exploration of regional and global cost-supply curves of biomass energy from shortrotation crops at abandoned cropland and rest land under four IPCC SRES land-use scenarios. Biomass Bioenergy 33(1):26-43. https://doi. org/10.1016/j.biombioe.2008.04.005

26. Stephen JD, Sokhansanj S, Bi X, Sowlati T, Kloeck T, Townley-Smith L, Stumborg MA (2010) The impact of agricultural residue yield range on the delivered cost to a biorefinery in the Peace River region of Alberta. Canada Biosystems Engineering 105(3):298-305. https://doi. org/10.1016/j.biosystemseng.2009.11.008

27. Sun JC, Chen JH, Xi YM, Hou JH (2011) Mapping the cost risk of agricultural residue supply for energy application in rural China. J Clean Prod 19(2-3):121-128. https://doi.org/10.1016/j.jclepro.2010.02.007

28. Li JJ, Ren DM, Zhuang X (2001) Systemic evaluation method of renewable energy resources and its practical application. J Nat Resour 16(4):373-380

29. Clare A, Shackley S, Joseph S, Hammond J, Pan G, Bloom A (2015) Competing uses for China's straw: the economic and carbon abatement potential of biochar. GCB Bioenergy 7(6):1272-1282. https://doi. org/10.1111/gcbb.12220

30. Xu XL, Chen YJ (2020b) A comprehensive model to analyze straw recycling logistics costs for sustainable development: evidence from biomass power generation. Environ Prog Sustain Energy 39(4):1-11. https://doi. org/10.1002/ep.13394

31. Rentizelas AA, Tolis AJ, Tatsiopoulos IP (2009) Logistics issues of biomass: the storage problem and the multi-biomass supply chain. Renew Sustain Energy Rev 13(4):887-894. https://doi.org/10.1016/j.rser.2008.01.003

32. Li J, Li G, Liu M, Zhu X, Wei L (2020) A novel text-based framework for forecasting agricultural futures using massive online news headlines. Int J Forecast. https://doi.org/10.1016/j.ijforecast.2020.02.002

33. Zhou J, Wu HT, Ding SJ, Zhu C (2011) Analysis of seasonal variation in crop residue harvest and sustainability of its energy supply. Resour Sci 33(8):1537-1545

34. Wu HT, Zhou J, Chen YP (2013) Analysis on sustainability of crop residue supply. China Popul Resour Environ 23(2):51-57

35. Xie GH, Wang XY, Ren LT (2010) Summary of research on China's crop residues resources evaluation. Chin J Biotechnol 26(7):855-863

36. Tack J, Barkley A, Nalley LL (2015) Effect of warming temperatures on US wheat yields. Proc Natl Acad Sci USA 112(22):6931-6936. https://doi. org/10.1073/pnas.1415181112

37. Fischer G, Shah M, Tubiello NF, Van Velhuizen H (2005) Socio-economic and climate change impacts on agriculture: an integrated assessment, 1990-2080. Philos Trans R Soc B Biol Sci 360(1463):2067-2083

38. Lioubimtseva E, Henebry GM (2009) Climate and environmental change in arid Central Asia: impacts, vulnerability, and adaptations. J Arid Environ 73(11):963-977

39. McDowell NG, Allen CD (2015) Darcy's law predicts widespread forest mortality under climate warming. Nat Clim Change 5(7):669-672. https:// doi.org/10.1038/Nclimate2641

40. Gaudin AC, Tolhurst TN, Ker AP, Janovicek K, Tortora C, Martin RC, Deen W (2015) Increasing crop diversity mitigates weather variations and improves yield stability. PLoS ONE 10(2):e0113261. https://doi. org/10.1371/journal.pone.0113261

41. Wichelns D, Oster J (2006) Sustainable irrigation is necessary and achievable, but direct costs and environmental impacts can be substantial. Agric Water Manag 86(1):114-127

42. Xun L, Wang P, Li L, Wang L, Kong Q (2018) Identifying crop planting areas using Fourier-transformed feature of time series MODIS leaf area index and sparse-representation-based classification in the North China Plain. Int J Remote Sens. https://doi.org/10.1080/01431161.2018.1492181 
43. Bhatt B, Rathore S, Lemtur M, Sarkar B (2016) Fuelwood energy pattern and biomass resources in Eastern Himalaya. Renew Energy 94:410-417

44. Li T, Hasegawa T, Yin X, Zhu Y, Boote K, Adam M, Bregaglio S, Buis S, Confalonieri R, Fumoto T, Gaydon D, Marcaida M 3rd, Nakagawa H, Oriol P, Ruane AC, Ruget F, Singh B, Singh U, Tang L, Tao F, Wilkens P, Yoshida $H$, Zhang Z, Bouman B (2015) Uncertainties in predicting rice yield by current crop models under a wide range of climatic conditions. Glob Change Biol 21(3):1328-1341. https://doi.org/10.1111/gcb.12758

45. Jonker J, Van Der Hilst F, Junginger $\mathrm{H}$, Cavalett O, Chagas M, Faaij A (2015) Outlook for ethanol production costs in Brazil up to 2030, for different biomass crops and industrial technologies. Appl Energy 147:593-610

46. Mbuthia LW, Acosta-Martinez V, DeBruyn J, Schaeffer S, Tyler D, Odoi E, Mpheshea M, Walker F, Eash N (2015) Long term tillage, cover crop, and fertilization effects on microbial community structure, activity: implications for soil quality. Soil Biol Biochem 89:24-34. https://doi.org/10.1016/j. soilbio.2015.06.016

47. Glithero NJ, Wilson P, Ramsden SJ (2013) Straw use and availability for second generation biofuels in England. Biomass Bioenergy 55:311-321

48. Yang XG, Chen F, Lin XM, Liu ZJ, Zhang HL, Zhao J, Li KN, Ye Q, Li Y, Lv S, Yang P, Wu WB, Li ZG, Lal R, Tang HJ (2015) Potential benefits of climate change for crop productivity in China. Agric For Meteorol 208:76-84. https://doi.org/10.1016/j.agrformet.2015.04.024

49. Andrews D, Kassam A (1976) The importance of multiple cropping in increasing world food supplies, American Society of Agronomy, Crop Science Society of America, and Soil Science Society of America.

50. Belanger G, Richards JE, McQueen RE (1992) Effects of harvesting systems on yield, persistence, and nutritive value of alfalfa. Can J Plant Sci 72(3):793-799

51. Rolz C, de León R, Mendizábal de Montenegro AL, Porras V, Cifuentes R (2017) A multiple harvest cultivation strategy for ethanol production from sweet sorghum throughout the year in tropical ecosystems. Renew Energy 106:103-110. https://doi.org/10.1016/j.renene.2016.12.036

52. Isbell F, Adler PR, Eisenhauer N, Fornara D, Kimmel K, Kremen C, Letourneau DK, Liebman M, Polley HW, Quijas S, Scherer-Lorenzen M (2017) Benefits of increasing plant diversity in sustainable agroecosystems. J Ecol 105(4):871-879. https://doi.org/10.1111/1365-2745.12789

53. McDaniel M, Tiemann L, Grandy A (2014) Does agricultural crop diversity enhance soil microbial biomass and organic matter dynamics? A metaanalysis. Ecol Appl 24(3):560-570

54. Xu XL, Chen HH, Feng Y, Tang J (2018) The production efficiency of renewable energy generation and its influencing factors: evidence from 20 countries. J Renew Sustain Energy 10(2):025901-025911. https://doi. org/10.1063/1.5006844

55. Wang LM, He KL (2006) Analysis on temporal variation of environmental impact based on STIRPAT Model-a case study of energy consumption of China. J Nat Resour 21(6):862-869

56. Xu XL, Liu CK (2019) How to keep renewable energy enterprises to reach economic sustainable performance: from the views of intellectual capital and life cycle. Energy Sustain Soc 9(1):1-10. https://doi.org/10.1186/ s13705-019-0187-2
57. Guan XL, Wei HK, Lu SS, Dai Q, Su HJ (2018) Assessment on the urbanization strategy in China: achievements, challenges and reflections. Habitat Int 71:97-109. https://doi.org/10.1016/j.habitatint.2017.11.009

58. Ding C, Lichtenberg E (2011) Land and urban economic growth in China. J Reg Sci 51(2):299-317. https://doi.org/10.1111/j.1467-9787.2010.00686.x

59. Xie H, Chen Q, Wang W, He Y (2018) Analyzing the green efficiency of arable land use in China. Technol Forecast Soc Change 133:15-28. https ://doi.org/10.1016/j.techfore.2018.03.015

60. China NBoSo (2018) China Statistical Yearbook. https://www.stats.gov.cn/ tjsj/ndsj/

61. MARAC (2018) China Agriculture Yearbook. https://english.agri.gov.cn/ service/ayb/

62. DESNBS (2018) China Energy Statistical Yearbook. https://www.china yearbooks.com/tags/china-energy-statistical-yearbook

63. Jia LW, Yang XS, Vecchi GA, Gudgel RG, Delworth TL, Rosati A, Stern WF, Wittenberg AT, Krishnamurthy L, Zhang SQ, Msadek R, Kapnick S, Underwood S, Zeng FR, Anderson WG, Balaji V, Dixon K (2015) Improved seasonal prediction of temperature and precipitation over land in a high-resolution GFDL climate model. J Clim 28(5):2044-2062. https://doi. org/10.1175/Jcli-D-14-00112.1

64. Dong HL, Chen Q, Wang WQ, Peng SB, Huang JL, Cui KH, Nie LX (2017) The growth and yield of a wet-seeded rice-ratoon rice system in central China. Field Crops Res 208:55-59. https://doi.org/10.1016/j.fcr.2017.04.003

65. Wang $X Y$, Xue $S$, Xie GH (2012) Value-taking for residue factor as a parameter to assess the field residue of field crops. J China Agric Univ 17(1):1-8

66. Shorrocks AF (2013) Decomposition procedures for distributional analysis: a unified framework based on the Shapley value. J Econ Inequal 11(1):99-126. https://doi.org/10.1007/s10888-011-9214-z

67. Wan GH (2004) Accounting for income inequality in rural China: a regression-based approach. J Comp Econ 32(2):348-363. https://doi. org/10.1016/j.jce.2004.02.005

68. Reed WR, Ye H (2011) Which panel data estimator should I use? Appl Econ 43(8):985-1000

69. Shorrocks AF (1982) Inequality decomposition by factor components. Econometrica 50(1):193-211. https://doi.org/10.2307/1912537

70. Fields GS, Yoo G (2000) Falling labor income inequality in Korea's economic growth: patterns and underlying causes. Rev Income Wealth 46(2):139-159

71. Chen MW, Jin HY, Gai QE, Shi QH (2016) Accounting for income inequality between households in rural China: a regression based approach. China Econ Q 15(3):1253-1274

72. Morduch J, Sicular T (2002) Rethinking inequality decomposition, with evidence from rural China. Econ J 112(476):93-106. https://doi. org/10.1111/1468-0297.0j674

\section{Publisher's Note}

Springer Nature remains neutral with regard to jurisdictional claims in published maps and institutional affiliations.

Ready to submit your research? Choose BMC and benefit from

- fast, convenient online submission

- thorough peer review by experienced researchers in your field

- rapid publication on acceptance

- support for research data, including large and complex data types

- gold Open Access which fosters wider collaboration and increased citations

- maximum visibility for your research: over 100M website views per year

At BMC, research is always in progress.

Learn more biomedcentral.com/submissions 